\title{
PENGARUH TEMPERATUR TERHADAP ISOMERISASI SENYAWA 3-CARENE MENJADI 4-CARENE DENGAN KATALIS NATRIUM-O-KLOROTOLUEN
}

\author{
Nurul Anisa, Tatang Shabur Julianto, Dwiarso Rubiyanto \\ Program Studi Ilmu Kimia, Fakultas Matematika dan Ilmu Pengetahuan Alam \\ Universitas Islam Indonesia \\ anisanurul0506@gmail.com
}

\section{INTISARI}

Telah dilakukan penelitian mengenai pengaruh temperatur reaksi pada konversi 3-carene menjadi 4-carene menggunakan katalis basa organik yaitu natrium-o-klorotoluen. Proses konversi ini dilakukan dengan metode isomerisasi dengan variasi temperatur reaksi $149{ }^{\circ} \mathrm{C}, 160{ }^{\circ} \mathrm{C}$, dan $178{ }^{\circ} \mathrm{C}$. Campuran yang digunakan adalah 3-carene dan xylene, natrium dan o-klorotoluen dengan perbandingan 1:1 yang direfluks pada temperatur $149{ }^{\circ} \mathrm{C}, 160{ }^{\circ} \mathrm{C}$, dan $178{ }^{\circ} \mathrm{C}$ selama 12 jam. Produk reaksi selanjutnya dianalisis menggunakan instrumen GC-MS.

Hasil penelitian menunjukan bahwa temperatur optimum konversi 3-carene menjadi 4-carene pada temperatur reaksi $178{ }^{\circ} \mathrm{C}$ dengan jumlah 4 -carene sebesar $49,8 \%$.

Kata kunci: 3-carene, isomerisasi, temperatur, natrium-o-klorotoluen.

\section{PENDAHULUAN}

Di Indonesia terpentin dihasilkan dari getah pinus jenis pinus merkusii. Terpentin dihasilkan sebagai hasil atas proses distilasi dan hasil bawahnya berupa gondorukem. Produk gondorukem dapat diolah lebih lanjut untuk bahan baku industri kosmetik, antiseptik, pereat, cat, dan lain-lain. Sedangkan terpentin dapat digunakan untuk bahan baku industri minyak cat, bahan pelarut, isolasi, farmasi, dan lain-lain.

Sebagian besar hasil dari minyak terpentin di Indonesia terkadang diekspor keluar negeri dan sebagian kecil dimanfaatkan di dalam negeri. Karena komponen utama dari terpentin adalah $\alpha$ pinene, sehingga lebih banyak disintesis. Selain $\alpha$-pinene terdapat juga 3-carene.
Salah satu upaya pengembangan 3-carene adalah dengan mengkonversi sebagian dari 3-carene menjadi 4-carene. 4-carene berperan dalam jalur sintesis memperoleh mentol dan isolimonen.

$$
\text { Metode isomerisasi 3-carene }
$$

menjadi 4-carene sendiri telah dikembangkan dari penelitian-penelitian sebelumnya. Penelitian yang telah dikembangkan 3-carene dapat disintesis menghasilkan 4-carene dengan bantuan katalis natrium Na-o-klorotoluen. Oleh karena itu, diperlukan penelitian lebih lanjut agar sintesis 4-carene ini dapat dilakukan secara efektif dan efisien. Metode isomerisasi menggunakan basa organik sebagai katalis. Untuk memperoleh 4-carene, peneliti melakukan isomerisasi senyawa 3-carene dengan 
variasi temperatur $149{ }^{\circ} \mathrm{C}, 160{ }^{\circ} \mathrm{C}$, dan 178 ${ }^{\circ} \mathrm{C}$. Agar mengetahui pengaruh temperatur terhadap reaksi isomerisasi dan temperatur mana yang merupakan temperatur yang optimum dalam proses isomerisasi 3carene menjadi 4-carene.

Keberhasilan penelitian ini dapat memberikan inovasi baru dalam memperoduksi turunan monoterpenoid yang lebih bernilai ekonomis tinggi dari senyawa induk 3-carene dengan metode isomerisasi menggunakan katalis yang lebih efektif dan ekonomis sehingga dapat dilakukan dalam skala besar. Selain itu dapat mengoptimalisasi pemanfaatan minyak terpentin yang pada umumnya hanya digunakan sebagai pelarut cat dan pewangi.

\section{METODE PENELITIAN}

\section{Bahan}

3-carene merck Sigma Aldrich, xylene merck J.T. Baker, natrium merck Sigma Aldrich, dan o-klorotoluen merck Schuchardt Ohg.

\section{Alat}

Seperangkat alat gelas, timbangan merck Ohaus, satu set alat refluks, termometer, pemutar magnet, penangas, dan GC-MS Shimadszu tipe 2010 QS

\section{Prosedur Penelitian}

\subsubsection{Isomerisasi 3-carene menjadi 4- carene}

Langkah isomerisasi 3-carene menjadi 4-carene menggunakan bahan utama 3-carene yang berasal dari komponen minyak atsiri dilakukan dengan mengikuti kondisi reaksi berikut:

Tabel 1. Tabel Variasi Temperatur

\begin{tabular}{|c|c|c|c|c|}
\hline $\begin{array}{c}\mathrm{T} \\
\left({ }^{\circ} \mathrm{C}\right)\end{array}$ & $\begin{array}{c}3- \\
\text { carene } \\
(\mathrm{mL})\end{array}$ & $\begin{array}{c}\text { Xylene } \\
(\mathrm{mL})\end{array}$ & $\begin{array}{c}\mathrm{o}- \\
\text { chloroto } \\
\text { luene } \\
(\mathrm{mL})\end{array}$ & $\begin{array}{c}\mathrm{Na} \\
\text { (gram) }\end{array}$ \\
\hline 149 & 10 & 10 & 0,3 & 0,3 \\
\hline 160 & 10 & 10 & 0,3 & 0,3 \\
\hline 178 & 10 & 10 & 0,3 & 0,3 \\
\hline
\end{tabular}

Campuran dimasukkan ke dalam labu leher dua kemudian diaduk dengan magnetic stirrer dan disiapkan penangas minyak. Campuran direfluks dengan variasi temperatur $149^{\circ} \mathrm{C}, 160^{\circ} \mathrm{C}$ dan $178^{\circ}$ C, sampai 12 jam. Selanjutnya hasil dari refluks didiamkan pada suhu kamar.

\subsubsection{Analisis Senyawa Hasil}

Hasil refluks yang diperoleh kemudian dianalisis menggunakan GC-MS tipe QP-2010 merck Shimadzu untuk mengetahui dan menentukan jumlah 3carene yang terkonversi menjadi 4-carene.

\section{HASIL DAN PEMBAHASAN}

Senyawa 3-carene dapat dikonversi dengan menggunakan basa kuat untuk menjadi isomernya yaitu 4-carene. Konversi 3-carene menjadi 4-carene ini memiliki sifat reaksi setimbang dan terjadi kesetimbangan pada reaksi konversi 3- 
carene menjadi 4-carene. Senyawa 4carene bukanlah komponen minyak terpentin yang biasanya berfungsi sebagai pelapis cat dan sebagainya, namun senyawa ini digunakan untuk konversi lebih lanjut menjadi senyawa terpenoid salah satunya adalah isolimonen.

Senyawa 3-carene berfungsi sebagai bahan utama untuk proses isomerisasi menghasilkan 4-carene, sedangkan xylene berfungsi sebagai pelarut yang non polar. Pemilihan xylene sebagai pelarut dikarenakan kekuatan pelarutan yang baik dan laju penguapan yang rendah. Natrium dan o-klorotoluen yang berfungsi sebagai katalis basa kuat organik.

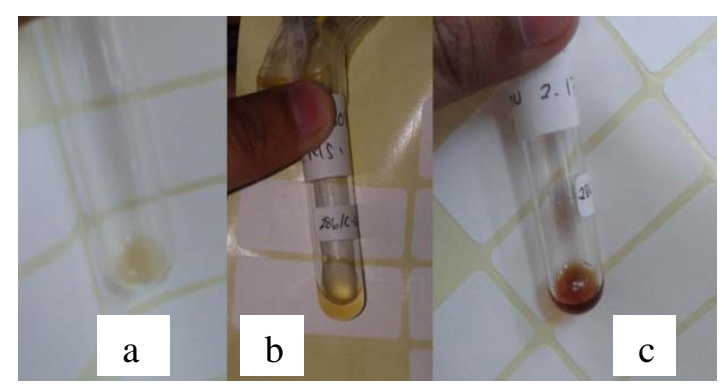

Gambar 1. Hasil refluks isomerisasi 3carene menjadi 4-carene (a) pada temperature refluks 149 ${ }^{\circ} \mathrm{C}$, (b) pada temperature refluks $160{ }^{\circ} \mathrm{C}$ dan (c) pada temperature refluks $178{ }^{\circ} \mathrm{C}$

Pada Gambar 1(a) menunjukkan hasil refluks senyawa 3-carene menjadi 4carene pada temperatur $149{ }^{\circ} \mathrm{C}$ ditandai dengan warna kuning bening sedangkan Gambar 1(b) menunjukkan hasil refluks senyawa 3-carene menjadi 4-carene pada temperatur $160{ }^{\circ} \mathrm{C}$ ditandai dengan warna kuning dan Gambar 1(c) menunjukkan hasil refluks senyawa 3-carene menjadi 4carene pada temperatur $178{ }^{\circ} \mathrm{C}$ ditandai dengan warna coklat tua. Jadi semakin tinggi temperatur warna hasil refluks yang diperoleh semakin coklat yaitu sudah terjadi reaksi sempurna.

\section{Hasil data GC senyawa 3-carene menjadi 4-carene}

Berikut adalah hasil GC pada isomerisasi senyawa 3-carene menjadi 4carene menggunakan katalis Na-oklorotoluen dengan temperatur refluks 149 ${ }^{\circ} \mathrm{C}, 160{ }^{\circ} \mathrm{C}$, dan $178{ }^{\circ} \mathrm{C}$ :

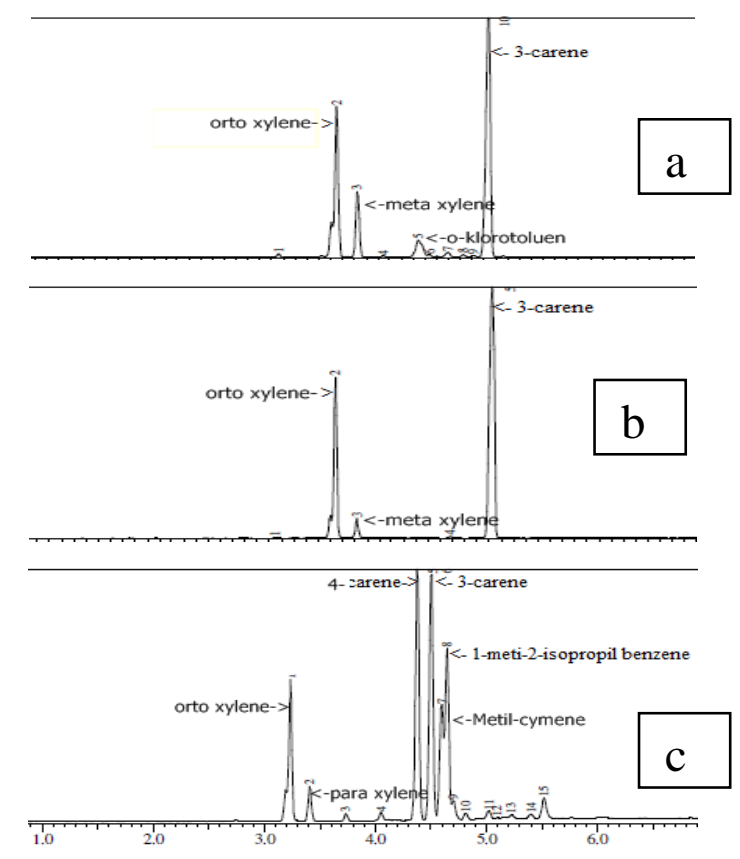

Gambar 2. Puncak Kromatogram hasil analisis 3-carene menjadi 4carene(a) pada temperatur 149 ${ }^{\circ} \mathrm{C}$,(b) pada temperatur $160{ }^{\circ} \mathrm{C}$ dan (c) pada temperatur $178{ }^{\circ} \mathrm{C}$ 
Gambar 2(a) menunjukkan bahwa pada puncak 2 dengan terdapat orto xylene, pada puncak 3 terdapat meta xylene, pada puncak 5 terdapat oklorotoluen dan pada puncak yang paling tinggi terdapat 3-carene. Pada percobaan pertama, temperatur refluks yang digunakan adalah $149{ }^{\circ} \mathrm{C}$. Pada temperatur tersebut tidak terbentuk 4-carene, hal ini disebabkan proses isomerisasinya tidak berereaksi sempurna sehingga tidak diperoleh senyawa 4-carene.

Gambar 2(b) menunjukkan bahwa pada puncak 2 dengan terdapat orto xylene, pada puncak 3 terdapat meta xylene, pada puncak 5 terdapat oklorotoluen dan pada puncak yang paling tinggi terdapat 3-carene. Pada percobaan kedua, peningkatan temperatur refluks hingga $160{ }^{\circ} \mathrm{C}$ tetap tidak menunjukkan senyawa 4-carene seperti pada Gambar 2(a).

Gambar 2(c) menunjukkan bahwa pada puncak 1 dengan terdapat orto xylene, pada puncak 2 terdapat para xylene, pada puncak 7 terdapat metil cymene, pada puncak 8 terdapat 1-metil-2isopropil benzena dan pada puncak 5 puncak yang paling tinggi terdapat 4carene, pada puncak 6 juga puncak yang paling tinggi terdapat 3-carene. Pada percobaan ketiga, temperature refluks yang digunakan adalah $178{ }^{\circ} \mathrm{C}$ menunjukan bahwa puncak yang tertinggi adalah 3carene dan puncak 4-carene hal ini disebabkan proses isomerisasinya berereaksi sempurna sehingga diperoleh senyawa 4-carene yang optimum yaitu dengan perbandingan 49,8\%:50,2\% pada 3-carene dan 4-carene. Penelitian ini menunjukkan bahwa hasil 4-carene yang diperoleh lebih besar dari pada penelitian sebelumnya. Data hasil GC senyawa dilampirkan pada lampiran 1.

1.

\section{asil data MS senyawa 3-carene menjadi 4-carene}

Berikut adalah spektum senyawa 3carene dan 4-carene pada isomerisasi senyawa 3-carene menjadi 4-carene dengan temperatur refluks $178{ }^{\circ} \mathrm{C}$ :

\section{a. 4-Carene}

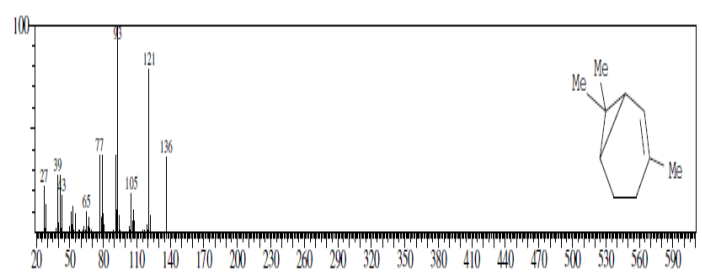

Gambar 3. Fragmentasi 5 dari senyawa 4-carene

Pola fragmentasi senyawa pada kromatogram menunjukkan bahwa senyawa pada puncak tersebut adalah 4carene memiliki rumus molekul $\mathrm{C}_{10} \mathrm{H}_{16}$ dan ion molekul 136 dengan tingkat kemiripan 93.

\section{b. 3-Carene}




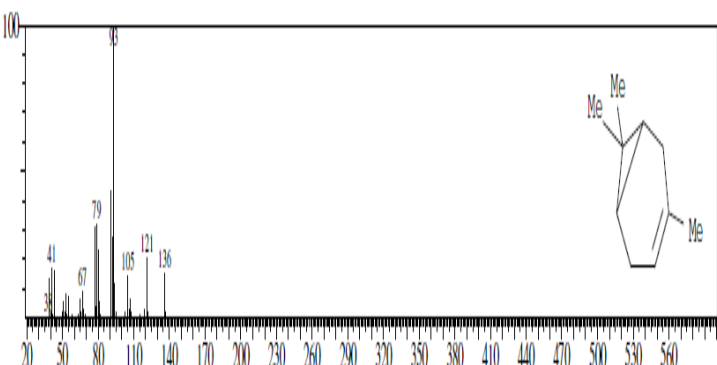

Gambar 4. Fragmentasi peak 6 dari senyawa 3-carene.

Pola fragmentasi senyawa pada kromatogram menunjukkan bahwa senyawa pada puncak tersebut adalah 3carene memiliki rumus molekul $\mathrm{C}_{10} \mathrm{H}_{16}$ dan ion molekul 136 dengan tingkat kemiripan 93. Senyawa 3-carene merupakan senyawa monoterpen bisiklik yang terjadi secara alami sebagai konstituen dari terpentin dan memiliki titik didih $168-170^{\circ} \mathrm{C}$.

\section{Mekanisme reaksi yang terjadi pada} isomerisasi 3-carene menjadi 4carene

Reaksi yang terjadi terhadap senyawa 3-carene menjadi 4-carene adalah isomerisasi, yaitu terbentuknya senyawa 4carene dengan bantuan katalis snatrium-oklorotoluen. Mekanisme reaksi yang terjadi sebagai berikut:
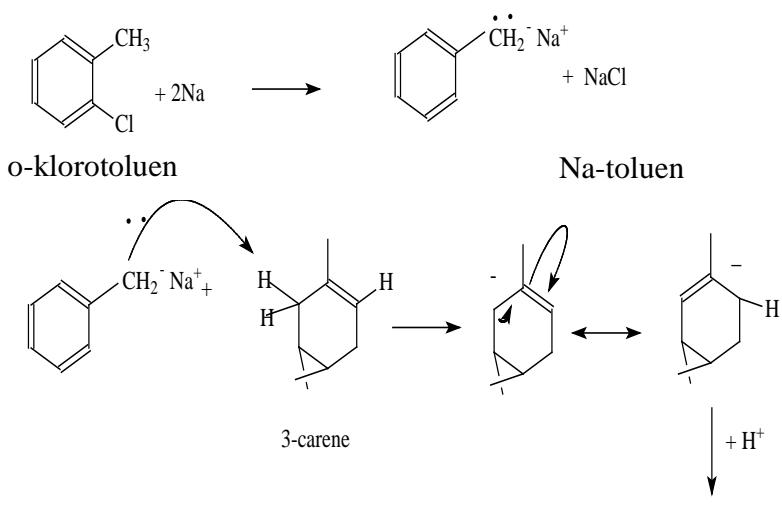

Volume 2

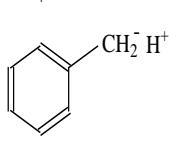

Gambar 5. Mekanisme reaksi isomerisasi terhadap senyawa 3-carene menjadi 4-carene menggunakan katalis natriumo-klorotoluen

Logam alkali seperti natrium jika bereaksi dengan senyawa organik cukup lamban sehingga dibutuhkan senyawa organik yang mudah bereaksi dengan natrium seperti o-klorotoluen. Oklorotoluen dapat membentuk turunan logam alkali dari hidrokarbon serta dapat menghasilkan katalis baru seperti turunan logam alkali dari alkohol dan amina biasanya dapat dibuat dengan reaksi langsung dari logam alkali dengan alkohol atau amina (Albert, 1986).

Gambar 5. reaksi yang pertama adalah reaksi katalisnya yaitu $\mathrm{Na}$ bereaksi dengan o-klorotoluen membentuk Natoluen. Sepasang elektron dari atom $\mathrm{H}$ berpindah ke $C$ sehingga atom $H$ bermuatan positif membentuk karbanion karena bermuatan negatif, lalu $\mathrm{Na}$ terikat dengan karbanion (1) erbentuklah $\mathrm{Na}$ toluen yang bertindak sebagai katalis. Reaksi kedua yaitu 3-carene dengan katalis Na-toluen yang akan membentuk 4-carene. Sepasang elektron berpindah ' 
ke C2 senyawa 3-carene sehingga C2 kelebihan elektron, atom $\mathrm{H}$ yang kekurangan elektron berikatan pada karbanion yang terbentuk lalu $\mathrm{Na}$ lepas (mengendap) sehingga ikatan rangkap pada C3 berpindah ke C4 dengan menambahkan $\mathrm{H}^{+}$dan terbentuk senyawa 4-carene.

\section{Konsep termodinamika dan kinetika} terhadap proses isomerisasi

Secara termodinamika, dapat diketahui dari aspek energi menunjukkan sistem kesetimbangan yang bersifat empiris. Energi dapat dipertukarkan antara sistem tertutup dan sekitarnya dengan melakukan kerja atau proses pemanasan. Pemanasan merupakan proses transfer sebagai kerja dan sebagai panas (Fatimah, 2010). Pengetahuan termodinamika sangat bermanfaat untuk memutuskan apakah struktur suatu senyawa akan stabil, kemungkinan kespontanan reaksi, perhitungan kalor reaksi, prenentuaan mekanisme reaksi dan penambahan elektrokimia. Dalam reaksi endoterm, energi yang diperlukan untuk memutuskan ikatan dan sebagainya disuplai dari luar sistem. Pada reaksi eksoterm, yang membebaskan energi, ternyata juga membutuhkan suplai energi dari luar untuk mengaktifkan reaksi tersebut (Atkins, 1991).
Dalam kinetika, suatu reaksi berlangsung melalui beberapa tahap. Diawali dengan tumbukan antar partikel reaktan. Setelah reaktan bertumbukan, maka akan terjadi penyusunan ulang ikatan dalam senyawa reaktan menjadi susunan ikatan yang berbeda (membentuk senyawa produk). Dalam penyusunan ini, akan ada pemutusan ikatan dan pembentukan ikatan yang baru, yang membutuhkan sejumlah energi. Ketika beberapa ikatan reaktan putus dan beberapa ikatan baru terbentuk, tercapailah suatu keadaan di mana dalam sistem terdapat sejumlah reaktan dan produk. Keadaan ini kita sebut sebagai transisi kompleks. (Vogel, 1994)

\subsection{Temperatur}

Isomerisasi termal ini berguna untuk memutus ikatan rangkap pada senyawa 3-carene yaitu C3 sehingga akan terjadi perpindahan ikatan rangkap ke C4 menjadi 4-carene. Konversi 3-carene menggunakan basa organik kuat sebagai katalis. Penggunaan katalis basa kuat supaya karbanion dapat terbentuk (Albert, 1968). Seperti pengaruh temperatur terhadap laju reaksi tergantung pada sifat termodinamika reaksinya, dimana pada temperatur $178{ }^{\circ} \mathrm{C}$ memiliki tingkat energi yang cukup tinggi pada proses berlangsung untuk memutus ikatan rangkap pada senyawa 3-carene yaitu C3 sehingga terjadi perpindahan ikatan rangkap ke C4 
menjadi 4-carene, sedangkan pada temperatur $149{ }^{\circ} \mathrm{C}$ dan $160{ }^{\circ} \mathrm{C}$ tidak memiliki tingkat energi yang cukup tinggi pada proses berlangsung sehingga tidak ada pemutusan ikatan rangkap dan perpindahan ikatan rangkap.

Temperatur optimum yang dapat digunakan untuk isomerisasi 3-carene menjadi 4-carene yaitu $178 \quad{ }^{\circ} \mathrm{C}$. Berdasarkan hasil yang diperoleh terlihat bahwa temperatur selama reaksi berlangsung sangat berpengaruh terhadap jalanya reaksi. Dengan menaikan temperatur maka energi kinetik molekulmolekul zat yang bereaksi akan bertambah sehingga akan lebih banyak molekul yang memiliki energi sama. Dengan demikian lebih banyak molekul yang dapat mencapai kecepatan reaksi menjadi lebih besar.

Temperatur juga berhubungan dengan energi kinetika yang dimiliki molekul-molekul reaktan dalam kecenderungannya bertumbukan. Kenaikan temperatur umunya menyediakan energi yang cukup bagi molekul reaktan untuk meningkatkan tumbukan antar molekul. Setiap partikel selalu bergerak dengan menaikkan temperatur, energi gerak atau energi kinetik partikel bertambah, sehingga tumbukan lebih sering terjadi dengan frekuensi tumbukan yang semakin besar, maka kemungkinan terjadiya tumbukan efektif yang mampu menghasilkan reaksi juga semakin besar.

\subsection{Katalis}

Selain temperatur katalis juga berperan penting karena katalis berfungsi untuk mempercepat laju reaksi kimia pada suhu tertentu, tanpa mengalami perubahan oleh reaksi itu sendiri, katalis bukan sebagai pereaksi ataupun produk, katalis menurunkan energi aktivasi sehingga jika kedalam suatu reaksi ditambahkan katalis, maka reaksi akan lebih mudah terjadi. Hal ini disebabkan karena zat-zat yang bereaksi akan lebih mudah melampaui energi aktivasi.

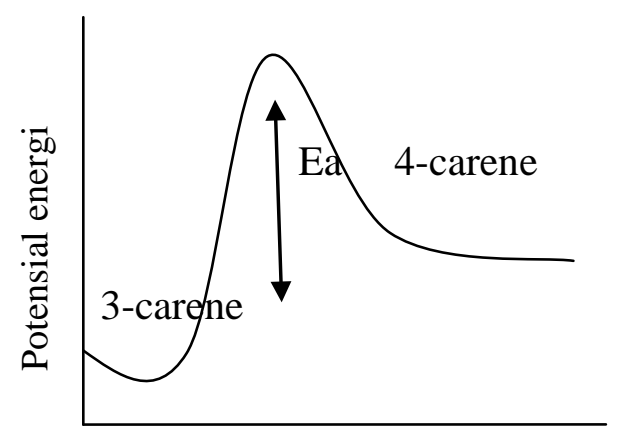

Gambar 6. Grafik energi aktivasi pada isomerisasi 3-carene menjadi 4-carene

Penelitian ini tidak dapat dihitung energi aktivasi (Ea) karena hanya ada satu sampel yang menghasilkan produk yaitu pada temperatur $178{ }^{\circ} \mathrm{C}$, sedangkan pada tempertaratur $149{ }^{\circ} \mathrm{C}$ dan $160{ }^{\circ} \mathrm{C}$ tidak menghasilkan produk 4-carene. Berdasarkan teori distribusi Maxwell- 
Bolzman, Temperatur dalam suatu sistem berkaitan erat dengan distribusi kinetika yang dimiliki oleh partikel yang ada dalam sistem tersebut. Gambar 6. menunjukkan menggambarkan distribusi banyaknya partikel dalam suatu sistem terhadap energi kinetika yang dimiliki saat temperatur dinaikkan, makin banyak partikel yang memiliki energi yang cukup besar untuk melampaui energi aktivitas.

Kehadiran katalis dalam suatu reaksi dapat memberikan mekanisme alternatif untuk menghasilkan hasil reaksi dengan energi yang lebih rendah dibandingkan dengan reaksi yang tanpa katalis. Energi pengaktifan yang lebih rendah menunjukkan bahwa jumlah bagian dari molekul-molekul yang memiliki energi kinetik cukup untuk bereaksi jumlahnya lebih banyak. Jadi kehadiran katalis adalah meningkatkan adanya tumbukan yang efektif, yang berarti juga memperbesar laju reaksi dilihat dari fasanya, katalis yang digunakan dalam penelitian ini dapat diasumsikan sebagai katalis heterogen.

\section{KESIMPULAN}

Dari hasil penelitian yang telah dilakukan maka dapat disimpulkan bahwa:

1. Temperatur berpengaruh terhadap reaksi isomerisasi 3-carene menjadi 4-carene karena semakin dinaikkan temperatur semakin terbentuk produk yang dihasilkan seperti pada temperatur $149{ }^{\circ} \mathrm{C}$ dan $160{ }^{\circ} \mathrm{C}$ tidak menghasilkan produk sedangkan pada temperatur $178{ }^{\circ} \mathrm{C}$ terbentuk produk.

2. Temperatur optimum dalam isomerisasi 3-carene menjadi 4carene adalah $178{ }^{\circ} \mathrm{C}$, dengan persen rasio 3-carene:4-carene sebesar 49,8\%:50,2\%, sedangkan pada temperatur $149{ }^{\circ} \mathrm{C}$ dan 160 ${ }^{\circ} \mathrm{C}$ tidak dapat terbentuk 4-carene karena proses refluks tidak berlangsung sempurna.

\section{UCAPAN TERIMAKASIH}

Penulis mengucapkan terima kasih kepada Bapak Tatang Shabur Julianto, M.Si., dan Bapak Dwiarso Rubiyanto, M.Si., yang telah memberikan kesempatan dan bimbingannya kepada penulis untuk dapat menyelesaikan penelitian ini, dan terima kasih kepada semua teman-teman yang telah membantu dalam penelitian ini.

\section{DAFTAR PUSTAKA}

Agusta, A., 2000, Minyak Atsiri Tumbuhan Tropika Indonesia. Bandung : ITB Press, 
Albert B, Booth, Jekyii Island, Ga., assignor to Hercules Incorporated, Wilmington, Del., a corporation of Delaware., 1968, Isomerization of 3-Carene to 4-Carene and Further Conversion of 4-Carene,(Cl.260-675.5). no patented 3,407,241.

Atkins, P.W., 1991, Kimia Fisika, Jilid 1, Edisi keempat, penerbit Erlangga: Jakarta.

Castellan G.W., 1982, Physichal Chemistry, Third Edition. New York : General Graphic Services

Geissman, T. A. dan Crout, D. H. G., 1969, Organik Chemistry of Secondary Plant Metabolism. Freeman, Cooper \& Company

Fatimah, 2013, Kimia Kinetika, Graha Ilmu, Yogyakarta.

Fatimah, 2010, Kimia Fisika, Universitas Islam Indonesia, Yogyakarta.

Fessenden, R. J., and J. S. Fessenden, 1982, Kimia Organik, Jilid 1, Edisi Ketiga, Penerbit Erlangga, Jakarta.

Fowlis, Ian A, 1998, Gas Chromatography Analytical Chemistry by Open Learning. John Wiley \& Sons Ltd: Chichester.

Pavia, Donald L., Gary M. Lampman, George S. Kritz, Randall G. Engel 2006, Introduction to Organic Laboratory Techniques (4th Ed.). Thomson Brooks/Cole. pp. 797-817.

Sastrohamidjojo, H., 2004, Kimia Minyak Atsiri, Liberty, Yogyakarta.

Skoog, Douglas A., Donald M. West, F. James Holler, 1991, Fundamental of Analytical Chemistry. Seventh Edition. New York: Saunders College Publishing.

Sanshiro, Komiya Ed., 1997, Synthesis of Organometallic Compounds: A Pratical Guide.

Stolle, Achim, Ondruschaka, 2009, Thermal Rearrangements of Monoterpenes an Monotepenoid, Friedrich-Schiller University Jena, Jena

Svehla, G, 1985. Analisis Anorganik Kualitatif. Jakarta. PT Kalman Media Pusaka, Bagian II.

Tarun K. Panda, Michael T. Gamer, and Peter W. Roesky, "An Improved Synthesis of Sodium and Potassium Cyclopentadienide", Organometallics 2003, 22, 877-878

Torseel, Kurt G. B., 1969, Natural Pruduct Chemistry. John Wiley \&Sons Limikal.

Vogel, 1994, Kimia Analisis Kuantitatif Anorganik. Jakarta : Penerbit Buku Kedokteran (EGC). 